IZA DP No. 8842

Do Negative Native-Place Stereotypes Lead to Discriminatory Wage Penalties in China's Migrant Labor Markets?

Margaret Maurer-Fazio

Rachel Connelly

Ngoc-Han Thi Tran

February 2015 


\title{
Do Negative Native-Place Stereotypes Lead to Discriminatory Wage Penalties in China's Migrant Labor Markets?
}

\author{
Margaret Maurer-Fazio \\ Bates College and IZA \\ Rachel Connelly \\ Bowdoin College and IZA \\ Ngoc-Han Thi Tran \\ Graduate Institute of International \& Development Studies
}

Discussion Paper No. 8842
February 2015

IZA
P.O. Box 7240
53072 Bonn
Germany

Phone: +49-228-3894-0

Fax: +49-228-3894-180

E-mail: iza@iza.org

\begin{abstract}
Any opinions expressed here are those of the author(s) and not those of IZA. Research published in this series may include views on policy, but the institute itself takes no institutional policy positions. The IZA research network is committed to the IZA Guiding Principles of Research Integrity.

The Institute for the Study of Labor (IZA) in Bonn is a local and virtual international research center and a place of communication between science, politics and business. IZA is an independent nonprofit organization supported by Deutsche Post Foundation. The center is associated with the University of Bonn and offers a stimulating research environment through its international network, workshops and conferences, data service, project support, research visits and doctoral program. IZA engages in (i) original and internationally competitive research in all fields of labor economics, (ii) development of policy concepts, and (iii) dissemination of research results and concepts to the interested public.
\end{abstract}

IZA Discussion Papers often represent preliminary work and are circulated to encourage discussion. Citation of such a paper should account for its provisional character. A revised version may be available directly from the author. 
IZA Discussion Paper No. 8842

February 2015

\section{ABSTRACT
Do Negative Native-Place Stereotypes Lead to Discriminatory Wage Penalties in China's Migrant Labor Markets?

China's linguistic and geographic diversity leads many Chinese individuals to identify themselves and others not simply as Chinese, but rather by their native place and provincial origin. Negative personality traits are often attributed to people from specific areas. People from Henan, in particular, appear to be singled out as possessing a host of negative traits. Such prejudice does not necessarily lead to wage discrimination. Whether or not it does depends on the nature of the local labor markets. This chapter uses data from the 2008 and 2009 migrant surveys of the Rural-Urban Migration in China Project (RUMiC) to explore whether native-place wage discrimination affects migrant workers in China's urban labor markets. We analyze the question of wage discrimination among migrants by estimating wage equations for men and women, controlling for human capital characteristics, province of origin, and destination city. Of key interest here are the variables representing provinces of origin. We find no systemic differences by province of origin in the hourly wages of male and female migrants. However, in a few specific cases, we find that migrants from a particular province earn significantly less than those from local areas. Male migrants from Henan in Shanghai are paid much less than their fellow migrants from Anhui. In the Jiangsu cities of Nanjing and Wuxi, female migrants from nearby Anhui are paid much less than intraprovincial Jiangsu migrants.

JEL Classification: J71, J23, J61, J31, O15, O53, P36

Keywords: migrants, discrimination, wages, China, stereotypes, native-place, labor markets

Corresponding author:

Margaret Maurer-Fazio

Bates College

276 Pettengill Hall

4 Andrews Road

Lewiston, Maine 04240

USA

E-mail: mmaurer@bates.edu 


\section{Introduction}

China is, as we all know, a very large, geographically diverse country. The sheer size of its land mass has important implications for physical mobility. Until the relatively recent improvements and investments in infrastructure and transportations systems, it took a tremendous amount of time to travel from one part of the country to another.

Additionally, spoken language differs across regions, such that Chinese people from one location may have difficulty understanding the spoken language of their fellow citizens from another location. In this setting, individuals do not simply identify themselves as Chinese, but rather they identify themselves more locally. When Chinese people meet for the first time, it is common to hear the question asked, 'Where is your lao jia (ancestral home)?' A typical first response is to name the province and then to follow up with more specificity. Thus, Chinese citizens often define their identity and the identity of others they meet in terms of their native place and by their province of origin. Personality traits are also broadly attributed to people from different provinces. Shanghai people are materialistic and good in business', 'Beijing people are bureaucratic, arrogant and hospitable', 'Sichuan people are hot tempered', and 'Henan people are untrustworthy'. Informants from differing locations may provide differing characterizations of people from particular provinces, but there seems to be a great deal of negative stereotyping across China when it comes to people from Henan. They are particularly singled out as possessing a host of negative traits (China Law and Governance Review 2006).

Henan rural-to-urban migrants feel this characterization daily as, according to contemporary media reports, they face more prejudice and ridicule than rural-to-urban migrants from other parts of China. They experience this prejudice in various ways, including job market discrimination and describe encountering job postings stating, 'Henan people need not apply' (Nanhu Evening News 2006). The source of this prejudice is sometimes attributed to a streak of bad publicity and sometimes to the sheer numbers of Henan migrants (Pottinger 2005; Shanghai Star 2005). Between 1990 and 2010, 10.5 million Henan residents migrated across provincial boundaries (Chan 2012). However, Anhui and Sichuan have sent similar, and even slightly higher, numbers of migrants to prosperous coastal regions without the same consequences. According to Pottinger, 
things got so bad that even in rural Sichuan, parents sometimes would tease their children: 'Behave yourself, or we'll send you to Henan'. And to escape the prejudice of their Beijing classmates, some Henan students sought to change the birthplace on their IDs (Shanghai Star 2005).

Such stories of province-of-origin-based identity, prejudice, and discrimination motivate the data analysis that undergirds this chapter. In it, we investigate the more limited question of whether there is evidence of native-place wage discrimination, based on province of origin, among rural migrants in China's urban labor markets. This research is important for understanding the contemporary experience of millions of ruralto-urban migrants in China. We hope it will provide insights about how urban China's migrant labor market functions that will be useful to policy makers considering changes to the current household registration system as well as to other interested parties.

The data used in this analysis come from the first two waves of the migrant surveys collected in 2008 and 2009 in China as part of the Rural-Urban Migration in China Project (RUMiC). ${ }^{1}$ The RUMiC Project is a very ambitious data collection effort specially designed to collect information about China's rural-to-urban migrant workers. The migrant sample was collected in 15 cities within 9 provinces and included both sending and receiving areas. Using the RUMiC data, we estimate standard Mincerian wage equations, ${ }^{2}$ which are supplemented with information on the migrants' province of

\footnotetext{
1 'The Longitudinal Survey on Rural Urban Migration in China (RUMiC) consists of three parts: the Urban Household Survey, the Rural Household Survey and the Migrant Household Survey. It was initiated by a group of researchers at the Australian National University, the University of Queensland and the Beijing Normal University and was supported by the Institute for the Study of Labor (IZA), which provides the Scientific Use Files. The financial support for RUMiC was obtained from the Australian Research Council, the Australian Agency for International Development (AusAID), the Ford Foundation, IZA and the Chinese Foundation of Social Sciences.'

${ }^{2}$ Mincerian wage and earnings functions, used to explore the determinants of earnings, are amongst the most widely employed empirical techniques in modern labor economics. They typically take the form of regressing the natural log of wages or earnings on years of schooling (or other measures of education) and on productive characteristics such as years of work experience and its square. It is commonplace to augment the basic Mincerian functional form with control variables that take account of demographic factors. See Mincer (1974) for a fuller account of the underpinnings of this empirical technique.
} 
origin. Since migrant labor is highly segregated by gender, we estimate the wage equations separately for men and women. We also control for destination cities and adjust wages to reflect the large differences in cost of living across China.

The rest of the chapter is as follows: Section 2 provides some background on the 'Great Migration' of China's rural residents to urban areas. It also reviews previous research on the determinants of migrant earnings. Section 3 reviews two basic economic models of discrimination and considers the predictions of these models in terms of wage discrimination among migrant workers in contemporary urban China. Section 4 provides a description of the data used in the analysis. There we also present summary statistics from the analytic sample with mean values for some of the key characteristics of male and female migrants. We also consider migrant flows to get a basic sense of 'who has come from where' in terms of the migrants living and working in the 15 cities sampled in the RUMiC project. Section 5 reports the results generated by estimating Mincer wage equations. Section 6 concludes the paper.

\section{Institutional context and literature review}

Starting in the 1950s, the Chinese leaderships adopted an economic growth strategy that emphasized the development of heavy industry and the support of urban workers at the expense of agricultural development and rural workers. To pursue this economic development strategy and to financially maintain its generous urban social welfare system, the Chinese leadership restricted and almost completely prohibited rural to urban migration. This agenda was carried out largely by means of the household registrations system (hukou), which continues to the present time and classifies individuals according to both residential locale and designated economic status. Each person's hukou records their place of presumed regular residence (suozaidi), that is, the place they belong to, as well as their status (leibie) - agricultural or non-agricultural. The latter classification is more typically referred to as rural or urban and itself determines an individual's eligibility for state-provided services, benefits, and jobs (Chan and Zhang 1999; Fan 1999). Migrants from rural areas working in cities are typically both away from their registered place of residence and classified as agricultural workers. 
In the socialist period, prior to the implementation of urban economic reforms, the hukou system in conjunction with the food rationing coupons effectively kept rural people restricted to living and working where they were born (Meng and Manning 2010). The restrictions on migration were relaxed, gradually, starting in the mid-1980s. In the early 1990s with both the abolishment of the food coupons and the growth of the manufacturing sector with its concomitant increase in the demand for labor, the flows of migrants from rural to urban areas gained momentum.

Looking back over the most recent three decades, between 200 and 250 million rural residents moved to China's towns and cities (Chan 2012). Rural migrant labor has become both an integral factor in the success of China's low-cost manufacturing industries and the mainstay of the low-end service sector. Despite central government relaxation of many of the historical restrictions on migration and the consequent massive contemporary flows of migrants, the legacy of those constraints continues to exert strong effects on the urban labor market. Urban officials are evaluated on local economic growth rates and the welfare of local residents and often effectively sacrifice the well-being of migrants to obtain better evaluations (Meng and Manning 2010). Thus, despite the implementation of the 2008 Labor Contract Law that intended to protect the rights of migrant workers and their access to benefits, they continue to be marginalized as secondclass citizens and/or guest workers.

Dual labor markets continue to exist in urban China. Urban residents with nonagricultural hukou status occupy the primary markets. Although the days of the almost permanent pairing of local workers to their work units (danwei) are over, primary labor markets are still characterized by longer job tenure, bonuses that constitute larger shares of annual compensation, and a higher probability of receiving employment benefits such as health insurance, pensions, and paid holidays. Urban workers also benefit from a legal system which tends to side with workers over firms in cases of contested terminations. Rural-to-urban migrants occupy the secondary labor markets, with much harsher working conditions. Their jobs are often characterized as dirty, dangerous, and demeaning. They 
are hired, fired, and laid off at will. They have lower pay and fewer benefits; work longer hours; and rarely obtain long-term contracts. ${ }^{3}$

Both push and pull factors affect rural residents' migration decisions. Lack of non-agricultural work opportunities push the migrants out of rural areas. Better pay and job vacancies in urban areas draw migrants to both local towns and cities and export processing areas. Chan $(2012,194)$ reveals that the net flows of migrants, at the provincial level, are unidirectional. Over the twenty-year period from 1990 to 2010 , the high growth, early developing Eastern seaboard provinces were net importers of migrant labor and the inland provinces were net exporters of rural migrant labor. By 2010, over 205 million rural residents resided in urban areas (Chan 2012, 190). Of these, 85 million had migrated across provincial boundaries and resided in provinces different from that on their official hukou registration. Net inter-provincial in-migration since 1995 has been dominated by Guangdong and Zhejiang who have attracted between 35 and 40 per cent of in-migrants. Sichuan, Anhui, Henan, and Hunan were the largest net exporters of rural labor between 2000 and 2010, each accounting for between 7 and 9 per cent of all interprovincial out migrants (Chan 2012). The patterns of inter-provincial migration during the decade of 2000-2010 are also extensively analyzed in Chapter 2 in this volume. The results in Chapter 2 indicate that coastal provinces in eastern China remained the main destination of the migrants and inland provinces continued to be the main sending regions. However, their analysis also indicates that the proportion of migrants absorbed by the eastern region declined in the years leading to the 2010 census, suggesting a shrinking migration flow to the eastern part of China.

While the net flows are unidirectional, the migration experience is still mostly circular for the migrants involved. While increasing numbers of migrants are settling in cities (Connelly et al 2011), most still return to their rural home after a few years. This

\footnotetext{
${ }^{3}$ Wang, Guo, and Cheng (2014) present an alternative perspective on the dichotomy of urban labor markets - based on data from a 2008 survey of four major cities, they carefully analyze the treatment of workers in urban areas along a local/non-local split in addition to the rural/urban split. They argue that hukou status still matters, but that in the recent period the aspect of local/non-local has become at least as important as the rural/urban dichotomy. They find labor market segmentation and wage discrimination against migrants along both dimensions, that is, rural migrant/urban local and local/nonlocal.
} 
means that many more people have had a migration experience than are currently in the urban areas. A significant portion of rural residents migrate repeatedly, some to the same locations, some to a variety of locations (Roberts et al 2004). The pull of wages differentials between sending and receiving areas is an important part of migrants' decision-making processes with respect to intended destinations (Hare 1999; Zhao 1999; Zhu 2003). While migrants from one sending area may typically go to one of a few receiving area, the flow is not completely deterministic. The variety of chosen destinations for migrants from each sending area can be viewed as evidence of agency on the part of the rural migrant decision makers.

An impressive number of empirical studies investigating the extent of labor market segmentation and wage discrimination in China's urban labor markets have focused on the migrant/urban resident dichotomy. In one early example, Meng and Zhang (2001) find that once the occupational distribution is taken into account, the entire pay gap between the migrants and urban residents of their Shanghai-based sample is left unexplained by productivity differences and is therefore presumably due to unfair treatment. Meng's (2002) exploration of the source of discrimination against migrant workers in six cities (Beijing, Nanjing, Wuhan, Xian, Tianjin, and Changchun) attributes their treatment to their status as 'outsiders' with no claims to enterprise profits. Knight, Song, and Jia (1999), based on a large multi-province, multi-city survey, find that the productivity of migrants exceeds their wages by a factor of more than three to one. Fan (2001) also reports that residence status functions as an ascriptive attribute in determining labor market outcomes. Maurer-Fazio and Dinh (2004) find that the human capital of urban residents is better rewarded on the whole than that of migrant workers. In contrast to the above, Demurger et al (2009) decompose data from the 2002 China Household Income Project and argue that migrants' labor market outcomes differ from those of urban hukou holders mainly because of differing productive characteristics rather than discriminatory treatment.

Frijters et al (2010) document a number of recent institutional changes implemented to eliminate open discrimination against rural migrants. After the implementation of the new 2008 Labor Contract Law, workers should have equal access to jobs; employers are supposed to pay minimum wages and full-time workers should be 
issued written contracts and those contracts should include information about social insurance. Frijters et al (2010) compare, based on the 2008 Urban and Migrant Household surveys of the RUMiC project, the characteristics and remuneration of a large number of migrants and officially registered urban residents. They report that migrants earn approximately 40 per cent less than urban residents. In addition, migrants receive only 16 per cent of the welfare benefits that urban residents get. They decompose the differences in both migrant and urban workers earnings and total compensation. They find that 46 per cent of the former and 51 per cent of the latter is left unexplained by differences in productive characteristics, and is rather attributable to differences in treatment. They also analyze the effects of being in particular destination cities on rural migrants' labor market experience. In the majority of the 15 cities in the RUMiC data set, they find that migrants are paid much less than they would be if compensated according to urban pay scales. However, they find that migrants are treated much more equally in two inland cities, Wuxi and Bengbu, than elsewhere. In these two cities migrants are compensated similarly to urban residents.

The above-mentioned studies have generated important, policy-relevant findings. However, these studies have all treated rural migrants either as a single group or separated them only by gender. A relatively new paper by Wang et al (2013) differs by distinguishing between urban migrants (those who have urban hukou status, but are not locally registered) and rural-to-urban migrants. Their study is based on a 2008 survey of four major cities and, like the other papers cited above, the goal is to compare the migrants' wages to urban resident wages. They find that all migrants are discriminated against in the provision of social security benefits such as pension eligibility, health insurance, and unemployment insurance. They find that more than half of the disparities in the provisions of work-related benefits between urban local residents and migrant workers are caused by discrimination against the latter. They also report that although both urban and rural-to-urban migrants are discriminated against, the extent of discrimination against rural-to-urban migrants is more severe. In a related study, Cheng et al (2013) find that rural-to-urban migrants suffer discrimination in both employment and wages, while urban migrants suffer discrimination only in terms of their wages. 
In this chapter, we focus only on rural-to-urban migrants (excluding urban migrants), looking within gendered groups of rural-to-urban migrants to explore whether migrant workers from particular provinces fare better or worse, after controlling for their productive characteristics, than those from other provinces in particular urban labor markets. As such, we compare rural migrants to rural migrants, but explore whether migrants' province of origin and relative localness affect their treatment in urban labor markets. Our analysis is perhaps closest to Zhang and Zhao (2013) who characterize rural migrants by the distance from their rural homes to their urban destinations. They find a positive income/distance relationship for both male and female migrants, which they consider as a compensating differential for migrants' strong preferences to be close to home rather than simply a reflection of transportation costs. But distance is not all that distinguishes one migrant from another. As our discussion above emphasizes, both employers and the migrants themselves may ascribe personal characteristics to rural-tourban migrants based on their province of origin. If employers and/or fellow workers believe that 'Henan ren dou bu hao' (no Henan people are good), ${ }^{4}$ then they may be discriminated against through lower wages.

\section{Economic theories of discrimination and predictions about observed wage differentials}

The most basic economic model of wage determination is that employers pay their employees according to their productivity. Thus, equally productive workers would receive equal wages. The wage level is determined by workers' productivity in their current endeavors, and is related to both the supply of workers of a certain quality and the demand for workers of that same quality. This simple 'first blush' model ignores institutional constraints, monitoring costs and the incentive-providing aspects of wages, and differences in how total compensation may be split between wages and benefits. These considerations may drive a wedge between compensation based purely on productivity and actual equilibrium wage levels, but even when such considerations are

\footnotetext{
${ }^{4}$ This phrase, 'No Henan people are good,' was uttered emphatically by a Beijing taxi driver to one of the co-authors of this paper after he discovered to his dismay that she was planning a trip to Henan to visit friends during the summer of 2013.
} 
included, the models still predict that workers with similar levels of productivity will be similarly compensated.

The term 'wage discrimination' may be used to describe the situation where workers with similar levels of productivity are compensated differently because of systematic, observable differences in ascriptive characteristics, that is, characteristics that do not affect productivity. There are two longstanding theories of wage discrimination: the 'taste for discrimination' theory (Becker 1957) and statistical discrimination (Phelps 1972). Becker's taste for discrimination theory hypothesizes that employers may simply dislike members of a certain group and be willing to 'pay' (in terms of forgone productivity) to avoid interactions with such groups. Similarly, according to Becker's theory, even if employers have no taste for discrimination, they may avoid hiring members of a certain group if their employees or customers dislike working with or dealing with members of that group. If the dislikes are stochastic, that is, if one person dislikes people with long fingers and another dislikes people with short fingers or some people dislike those with red hair, but few others share these dislikes, then no wage differentials will be observed. However, if the dislikes are commonly held, such that a large portion of the population agrees, for example, that Henan people cannot be trusted, then the 'taste for discrimination' theory predicts that members of that group will receive systematically lower wages.

The theory of statistical discrimination focuses on the asymmetrical information problems employers' face in making hiring and compensation decisions. An employer may not be able to observe a given worker's exact productivity. When actual productivity cannot be observed, the employer will rely on his/her sense of the average productivity of a group of workers. The individual employee is lumped into a group based on some easyto-observe characteristic. In China, province and place of origin are characteristics inscribed on individual shenfenzheng (ID cards), and thus, readily available to potential employers. Accordingly, if an employer believes all Henan people are untrustworthy, he/she would be not willing to hire a given migrant from Henan without discounting his or her wages.

Ultimately then, both of these economic theories of discrimination lead to the same testable prediction: given a widespread consensus of prejudice against a particular 
group, wages will be systematically lower for this group's members. However, if the cause of the wage discrimination is statistical discrimination, then the theory predicts that wage differentials will disappear in situations where employers are able to more easily observe the individual's actual productivity. It is possible that the labor market of ruralto-urban Chinese migrants is one where quite a bit of information about an individual's productivity is readily available, given that workers come and go frequently, that much of the work is physical and more easily monitored, and that labor contracts are short. In this situation it is possible that productivity is easy to observe and that, despite commonly held views depreciating certain groups, wage discrimination will not be observed. On the other hand, if intermediaries such as labor market recruiters, simultaneously hire groups of workers to do a particular task or type of work without observing the workers' productivity, we would expect more statistical discrimination and wage discrimination to emerge.

In the end it is an empirical question whether wage discrimination will be observed among the rural-to-urban migrants currently employed in Chinese urban labor markets. Evidence of widely held prejudice is a necessary but not sufficient condition for wage discrimination. The nature of the labor market itself and the type of jobs migrants do are also expected to affect the outcome.

Since these factors differ substantially across China, we allow for regional differences in outcomes in the empirical analysis that follows. We first provide an analysis of the differences in migrants' wages based on the full data set. We include the intra-provincial migration of those with agricultural hukou who move to large urban centers in our full migrant sample. Some other analysts focus on inter-provincial migration only. Next, we carefully define and track the destinations of the migrants from each of the five sending provinces in our data. We then separately analyze how the migrants from each of these provinces fare, in terms of wages received, in the places to which they chose to migrate. Again we include intra-provincial destinations. Thus, for example, when we focus on male migrants from Henan, we see that their most popular destination cities (of the cities included in the RUMiC data) include Zhengzhou and Luoyang (both located in Henan) as well as Hangzhou, Dongguan, and Shenzhen. Here we focus on how the Henan migrants fare in comparison to the others who have also 
chosen to migrate to this set of five cities. We carry out analogous analyses for the migrants from each sending province, each with their individually defined sets of destination cities. In the final analytical portion of our paper, we focus, separately, on each of the migrant-receiving provinces. In this section we explore whether employers in these prosperous, high labor demand, migrant-attracting regions treat migrants with similar skills from differing native places differently. 


\section{Data, migrant flows and empirical strategy}

The ongoing RUMiC project has focused on collecting information on the causes and consequences of migration in modern China. As such, data was collected in rural areas for rural residents and in urban areas for both urban residents and rural-to-urban migrants. For the rural and urban resident samples, regular sampling frames were employed. Residence based sampling frames often fail to adequately capture migrants, given that many live on works sites and often do not register their residence. The survey team thus developed a new sampling strategy that involved a unique pre-survey census of businesses in randomly chosen areas of each city included in the project. Additional procedures were applied to ensure that migrants working at occupations such as taxi drivers and domestic servants, those unlikely to be captured by enumerators visiting workplaces, were included in the census. The migrant survey was administered to a random selection of the migrants identified in the census (Kong 2010; Akgüç, Giulietti, and Zimmerman 2014). Initially in 2008, 5007 households were surveyed including 8446 individuals. Our data sample combines information from both the 2008 and 2009 migrant surveys. While the 2009 data collection was intended to be longitudinal, high attrition from the 2008 migrant sample led the survey designers to add 3422 new migrant households and 5426 new migrant individuals to the sample. We do not double count migrants from these two survey years. We include all the employed migrants in the 2008 sample who are between the ages of 16 and 65 and then add the newly sampled wage and salary migrants of the same age group from the 2009 survey.

We restrict the sample used to employed individuals between the age of 16 and 65. We exclude self-employed migrants out of a concern that their earning may reflect both returns to their productivity and to capital. We similarly exclude those working without pay in family businesses. Table 1 reveals the home province of all the migrants thus selected. This list of 10 main source/home provinces remains unchanged even if we were to include all the self-employed migrants and those working in unpaid family businesses.

(Table 1 about here.) 
In order to fully explore province-of-origin wage differences among working rural-to-urban migrants, we employ a three-prong empirical strategy. We first estimate wage equations for male and female migrants based on our whole analytic sample. This allows us to test for widespread, national-level discrimination in wages against migrants from particular provinces. We control for productive characteristics such as migrants' years of schooling, years of work experience, and tenure on current job. We also control for migrants' marital status as recent empirical work has revealed that in China married men tend to earn premiums over single men and married women are penalized relative to single women (Hughes and Maurer-Fazio 2002). Given the marked differences in the cost of living in different regions of China, we deflate our hourly wage rates with an urban provincial price deflator (Brandt and Holz 2006) ${ }^{5}$ and also include controls for destination cities. Of key interest are the effects of migrants' province of origin on their wages, all else equal. We control for these effects by including a set of categorical variables indicating the migrants' home province.

(Table 2 about here.)

In the second prong of our strategy, we narrow our focus to explore how the migrants from particular sending provinces, that is, provinces known as net exporters of rural labor, fare relative to others in the particular destinations where they land. For example, as Table 2 reveals, in the RUMiC data, male and female migrants from Anhui who may be present in any of the 15 cities included in the dataset, overwhelmingly are found in six particular cities: Hefei, Bengbu, Shanghai, Nanjing, Hangzhou, and Ningbo. ${ }^{6}$ Ninety four per cent and 92 per cent of our male and female Anhui migrants, respectively, are working in this set of cities. Migration patterns differ substantially by sending area. We note, for example, that among the 15 cities in the dataset, although male

\footnotetext{
${ }^{5}$ Brandt and Holz (2006) report regional urban and rural spatial price deflators for China. They have updated these deflators to 2010 and generously made them available at: http://ihome.ust.hk/ socholz/SpatialDeflators.html.

${ }^{6}$ Of these popular destinations for Anhui migrants, both Hefei and Benbu are located in Anhui.
} 
migrants from Henan, Sichuan and Hubei commonly migrate to the migrant-receiving cities of Guangdong (Shenzhen, Dongguan, and Guangzhou), Anhui men do not. In this part of our analysis we focus, sequentially and separately, on how male and female migrants from Henan, Anhui, Sichuan, Jiangsu, and Hubei fare in the sets of cities, including those within their home province destinations, to which they migrate. ${ }^{7} \mathrm{We}$ don't, however, analyze why, for example, Anhui migrants chose these destinations. We focus instead on whether they receive similar treatment in these locations to that received by migrants in these same destinations who come from differing home provinces. For this part of our analysis, the set of receiving cities typically differs for male and female migrants from each sending province. With the exception of Anhui, we find that female migrants from each of these main sending areas tend to migrate to fewer locations than their male counterparts. We acknowledge that our sample of female migrants is smaller than that of male migrants, but suspect that the results are real in that female migrants are sticking a bit closer to home. We use the criteria that at least 30 migrants from a particular sending area (say Anhui) end up in a specific destination to include that destination in the definition of the relevant receiving area for those particular migrants. Once we've defined the relevant geographic region to which migrants from each of our sending provinces migrates, we estimate a wage regression on that subset of our data. We include the same set of control variables as we do for the national-level wage regressions. The set of categorical controls for home province (our variables of key interest) varies both for each of the five sending areas and by gender. We include a named categorical control variable for each sending province that has at least 20 migrants in the specified receiving areas. All others are aggregated into a residual category, 'other province'.

(Table 3 about here.)

\footnotetext{
${ }^{7}$ One must be careful in the interpretation of Table 2. It is not representative of the flow of all Chinese rural-to-urban migrants from these sending provinces in 2008/2009 since only 15 cities are included in the data. Beijing and Tianjian are notably absent. Instead, Table 2 represents the patterns of migration from these five sending areas to the 15 cities included in the sample. Nonetheless, the differences in the destinations of migrants from different sending provinces are clear.
} 
In the third prong of our analysis, we focus on how migrants' wages compare in key migrant receiving provinces: Guangdong, Zhejiang, Jiangsu, and Shanghai. In this section of our analysis, we explore whether migrants are treated more or less equally in particular geographic regions known as migrant receiving areas. As Table 3 reveals, some areas draw migrants from a wider circle than other areas. ${ }^{8}$ The dispersion of home provinces for migrants in Guangdong appears to exceed those of the other 3 receiving provinces, at least in terms of the migrants sampled in the RUMiC data. ${ }^{9}$ Once again, we include the same set of controls and focus on the categorical variables representing migrants' home provinces as we explore whether migrant wages are affected by province of origin in these more migrant-receiving labor markets.

(Table 4 about here.)

As the summary statistics of Table 4 reveal, the rural-to-urban migrant men and women who are wage and salary workers are remarkably similar (and perhaps to some, surprisingly similar) in terms of both their work and migration characteristics. The men are, on average, only about 1 year older than the women with mean ages of 29 and 28 , respectively. Forty-nine per cent of the women are married, as are 46 per cent of the men. The years of education are also similar for men and women. These migrants, on average, have middle school educations. Given their ages and their mean years of work experience, it appears that many of these migrants started work at approximately age 16. The men typically have a year more of migration experience than their female counterparts (they are a year older). Similarly, the men are marginally more likely to have experience migrating to more than one city than have the women. The mean hourly earnings of women is 5.7 yuan, while men's mean hourly earnings is 6.8 yuan. Male migrants work about 2 hours more per week than the women and thus earn approximately 300 yuan more per month than do the female migrants, due to the slightly longer hours of work and the higher hourly wage.

\footnotetext{
${ }^{8}$ Since this analysis is based on current location, we can claim that the results in Table 3 are representative of all the rural-to-urban migrants in these receiving cities.

${ }^{9}$ Guangdong also differs from the other receiving areas in that 70-80 per cent of the labor force of its export processing centers, Shenzhen and Dongguan, is made up of migrant labor (Chan 2012).
} 


\section{Multivariate analysis of the determinants of earnings: Is there evidence of wage discrimination for migrants from some provinces?}

Full analytic sample - As argued above, although there appears to be widespread negative stereotyping of Henan people across China, such prejudice will not necessarily translate into wage discrimination for migrants from Henan in the urban labor markets to which the migrants relocate. The outcome will depend on the nature of the labor market in which the migrants find themselves. As described above, we estimate Mincerian wage equations to test for systematic differences in migrants' wages across provinces of origin. The dependent variable is the natural log of hourly earnings adjusted for differences in the cost of living across provinces and survey years (Brandt and Holz 2006). In addition to the set of categorical variables indicating migrants' province of origin, we also include as independent variables: years of education, years of overall work experience and work experience squared, years at current job, a dichotomous variable which takes on the value of one if the migrant is currently married, and a dichotomous variable which takes on the value of one if the observed earnings come from 2008 (rather than 2009). ${ }^{10} \mathrm{We}$ also control for migrants' city of current residence as fixed effects. Given compelling evidence in the literature that men and women's labor markets are quite segregated, we estimate our fixed effects regressions separately for male and female migrants.

(Table 5 about here.)

The results from our full sample of all rural-to-urban migrants in the 15 cities, controlling for province of origin, reveal difference between male and female migrants. As shown in Table 5, there is no overlap in men and women's statistically significant provinces of origin. Controlling for the unobserved fixed effects of each city, we find that female rural-to-urban employed migrants from Anhui, Henan, and Jiangsu all earn about

\footnotetext{
${ }^{10}$ We control whether the migrants' earnings are those reported in 2008 for the migrants from the 2008 wave of the RUMiC survey or those reported in 2009 for the newly added migrants from the 2009 wave of the survey to allow for changes in underlying economic conditions between survey years.
} 
10 per cent more than female migrants from Chongqing, which is our basis of comparison. We note that although female migrants from Henan may be negatively stereotyped in the media, their wages are higher than those of most of the other female migrants in the sample and statistically akin to those from Anhui and Jiangsu. Both Anhui and Henan are low-income provinces and major sending areas. Jiangsu includes both sending and receiving areas as northern Jiangsu's economic development lags behind the economically prosperous, southern Jiangsu, which includes the receiving cities of Nanjing and Wuxi.

Employed migrant men from Zhejiang earn about 17 per cent more than men from Chongqing, while men from Hubei, Hunan, and Jiangxi earn about 9 per cent less, and those from Guangxi 14 per cent less than those from Chongqing. Our results indicate that migrant men from Henan province are treated similarly to those from Chongqing. They do not stand out, after controlling for their productive characteristics, as receiving either advantageous or discriminatory treatment in terms of their wages.

That particular provinces of origin yield different advantage and/or disadvantage for men and women does not imply that all wage determinants differ between men and women. Marriage, however, does differentially affect men and women's wages. Being married reduces migrant women's earnings by about 4 per cent, but increases migrant men's earnings by 4 per cent. ${ }^{11}$ Male and female migrants receive similar returns to years of education--approximately 5 per cent per year of schooling. These 2008/2009 rates of return to education are higher than those based on earlier data for migrant workers found by Maurer-Fazio and Dinh (2004) perhaps indicating a maturing of the migrant labor market in urban China. Returns to years of overall work experience and years of experience at the current job are very similar for men and women. Finally, the increase in wages between 2008 and 2009 is also approximately the same for men and women. That both male and female migrants are rewarded according to these productivityenhancing characteristics is evidence that economic models of wage determination do explain some of the differences in earnings. It is clear that in 2008/2009, employers differentiate migrants by their education and work experience. In addition, we see that the R-squared values, which indicate the proportion of the variation in log wages

${ }^{11}$ This is consistent with the results of Hughes and Maurer-Fazio (2002). 
explained by the included observable characteristics, are quite high (for this type of regression) at around 26 per cent.

What can we conclude from the province-of-origin results in this full sample analysis? First, we conclude that there is no overall systematic discrimination in wages against people from Henan. We find for women, that Henan migrants have significantly higher earnings than those from Chongqing province, our base case. For men, we find no significant difference between the wages of migrants from Henan and Chongqing. In addition, although we might suspect that if the men from a particular sending province are discriminated against that the women from the same province would also receive discriminatory wages, there does not seem to be a strong pattern of significant difference across gender for any of the sending provinces

Our null hypothesis is that there is no systematic wage discrimination based on place of origin across the 15 cities of the full sample. Our main conclusion is that we have not found evidence that would cause us to reject this null hypothesis. Our full regression results provide evidence that employers are able to observe differences in productivity. They do not rely simply on migrants' province-of-origin in setting wages. However, it may be that regional differences in wage discrimination exist and that the full analytic sample results are masking regional differences. To test this hypothesis we turn now to regional earnings equations. The regions tested are designated in two ways: first by defining the five separate subsets of cities favored by the migrants from each of the five main sending provinces and then in terms of the four key receiving provinces.

Main sending provinces-In Section 4 of this chapter, we showed that the patterns of migration from sending to receiving areas differ by sending province. Anhui is the largest source of migrants in the RUMiC data for men and the second largest for women, providing about 15 per cent of both the men and women's analytic samples. The main receiving cities of these Anhui men and women are Hefei, Bengbu, Shanghai, Nanjing, Hangzhou and Ningbo. Hefei and Bengbu are the large cities in Anhui province; Hangzhou and Ningbo are both in Zhejiang province. In contrast, as shown in Table 3, Henan is the second largest source of migrants in the sample for men and the fifth largest for women. Henan men migrate to the Henan provincial cities of Zhengzhou and 
Luoyang and to Hangzhou, Dongguan and Shenzhen. Beyond the Henan provincial cities of Zhengzhou and Luoyang, Henan women go to Shanghai and Hangzhou. At this stage of the analysis we focus on the question, how do Henan-origin migrants fare in the cities to which they migrate in comparison to other migrants who migrate to these same cities? In asking this question we are agnostic on the reason for their destination choice. They may go where they do because it is close, because they can command higher wages there than elsewhere, or because others from their village have gone there before. Regardless of why they go where they go, we are interested in how the wages of migrants from a given sending province compare to the other migrants in those same destination cities, that is, with their labor market competitors and counterparts from other places.

\section{(Table 6 about here.)}

Table 6 shows the wage equation results for all migrants in the same areas to which Henan migrants go in large numbers. For men, the area is aggregated to include Zhengzhou, Luoyang, Hangzhou, Dongguan and Shenzhen. The area to which Henan women migrate in large numbers includes Zhengzhou, Luoyang, Shanghai and Hangzhou. In these two regressions, the omitted province-of-origin for both men and women is Henan. Thus, the provincial coefficients tell us how much more or less the other rural-to-urban migrants earn in comparison to Henan migrants in the cities to which Henan people migrate (including home province cities). If there were systematic wage discrimination against Henan migrants in the places Henan migrants go, then all of these provincial dummy variables should have positive, statistically significant coefficients. For women, none of the provincial coefficients are significantly positive. Instead, we find the Henan migrant women earn more than Jiangsu migrant women in the group of cities where Henan women tend to go. Similarly, Henan female migrants earn more than female migrants from the provinces sending small numbers of women, the residual 'other province' category. For men, we find a large premium for migrants from Zhejiang and also from Chongqing compared to Henan men, but no significant differences between Henan men and men from any of the other provinces. Most telling, in terms of the wage discrimination hypothesis is that Henan men's wages are not different from men from the 
other provinces that send large numbers of male migrants. If there were wage discrimination targeted at Henan men particularly, we would expect their wages to be lower than the wages of men from Anhui, Sichuan, Hubei or Jiangsu.

We repeated this main sending province analysis for the four other main sending provinces: Anhui, Sichuan, Jiangsu and Hubei. ${ }^{12}$ As described in Section 4, in each case, the sample is defined as the cities to which male and female migrants (separately) tend to migrate. Then the earnings of migrants of the focal sending provinces are compared to the earnings of the other migrants in those same cities. For women, there are almost no statistically significant differences in any of the four additional analyses. Only in the cities to which the women from Jiangsu tend to migrate (Nanjing, Wuxi, and Shanghai) do women from Jiangsu earn significantly more than women from Sichuan and Shandong. These findings along with the Henan women's results seems to refute the finding of Zhang and Zhao (2013) of a positive relationship between distance and earnings for women. In both of these cases, local female migrants earn more than their counterparts from more distant provinces of origin. Across our analyses of all five sending areas, we find no evidence of systematic regional wage discrimination for women by place of origin.

For men, in terms of these sending area regressions, we find no significant differences in how men from Sichuan are paid in comparison to migrants from any of the included provinces of origin in the cities where the Sichuan men tend to migrate. The same is true for the cities where Hubei men migrate. In the other two groupings, for migrants from Anhui and Jiangsu, respectively, there are some significant differences in their earnings in comparison to migrants from other provinces. Again, we find that in both of these regressions the men from Zhejiang do better than others. The differentials are quite large, 23 per cent higher wages for Zhejiang men compared to men from Anhui and 22 per cent higher compared to men from Jiangsu. Anhui men also earn much less than migrants from Fujian, but more than migrants from Hubei. Jiangsu men earn more than men from Hubei, in the group of cities where Jiangsu migrate. There are not enough

\footnotetext{
${ }^{12}$ While restrictions on the chapter's length precluded inclusion of these tables, the results of the regressions for both male and female migrants from the other four sending areas are available from the authors on request. (Appendix Tables A.1-A.4)
} 
male migrants from Anhui or Jiangsu in the cities where Hubei migrants go (Wuhan, Dongguan, Shenzhen) to allow us to make the comparison in the other direction.

The strong result that Zhejiang men are being paid more than those from other provinces, holding education and work experience constant, across three of our five analyses of sending provinces (Henan, Anhui and Jiangsu) seems to indicate that these results for men have more to do with Zhejiang migrants than with whom they are being compared and which group of cities is being considered. Zhejiang migrants command higher wages than migrants from any other province and in each location where there are enough Zhejiang natives to allow us to put in a control variable. Since Zhejiang is a coastal province with relatively high per-capita income in the rural areas, the pull factors must be quite strong to induce them to migrate. In this sense we are observing a much more selected group of migrants from Zhejiang than other provinces. In addition, the wealth of the province may mean that Zhejiang migrants bring physical capital with them when they migrate, while most other rural-to-urban migrants supply only their raw labor.

It is difficult to generalize the rest of the place of origin results for men. It seems that locals in Anhui and Jiangsu, that is, same province migrants, have some advantages against migrants from Hubei (farther away), a phenomenon we also find in the women's results. The overlapping nature of the cities in the regions we have defined for migrants from sending provinces makes it difficult to make more definitive statements. Thus, we now turn now to analyses focused on receiving, rather than sending, areas.

Receiving areas - In this final subsection of our analysis, we again consider regional differences in the earnings effect of the province-of-origin identities of rural-tourban migrants. However, in this section each of our subsamples is defined as one of the receiving provinces. In each these analyses, we group together the receiving cities within a province, treating the province as the destination (but continuing to include fixed effects for destination cities). These receiving areas are: Jiangsu (including Nanjing and Wuxi), Zhejiang (including Hangzhou and Ningbo), Guangdong (including Guangzhou, Dongguan and Shenzhen) and Shanghai. Once again, we focus our analysis on differences in pay by province-of-origin. And again, we limit the number of provincial 
indicators in each regression to those for which we have at least 20 migrants in the working sample. All others are grouped into a residual, 'other province' category.

(Tables 7a, 7b, 7c and 7d about here)

Table 7a presents the regression results for Guangdong as a receiving area. Migrants from other provinces are compared to those from Guangdong (that is, Guangdong is the omitted category). We find no significant differences by province of origin for women. For men, we find that migrants from Guangxi earn significantly less than those from Guangdong, while men from 'other provinces' earn significantly more. The earnings of Henan male and female migrants are not significantly different from those of local migrants from rural Guangdong.

Table $7 \mathrm{~b}$ repeats the analyses for Zhejiang as the receiving destination. Here we have not made Zhejiang the omitted category because of our previous strong result that Zhejiang migrants seem to do consistently better in every labor market. By making Anhui the omitted category in this analysis, we can observe how Zhejiang migrants do compared to Anhui migrants, this time on their home turf. Anhui is the modal province of origin in the men's sample (20 per cent of the men's migrant sample currently in Zhejiang came from Anhui), with intra-provincial Zhejiang migrants a close second (18 per cent). For women, 20 per cent of the migrants in urban Zhejiang come from rural Zhejiang and 18 per cent come from Anhui. Our regression results reveal that, once again for women, no province-of-origin controls are significant. For men, we find that intraprovincial Zhejiang migrants who have moved to the cities of Hangzhou and Ningbo earn 16 per cent more than their counterparts from Anhui. Jiangsu and Hubei men have significantly lower wages than Anhui migrants in Zhejiang. The earnings of the migrants from Henan in Zhejiang do not differ significantly from their Anhui counterparts for either men or women.

Table 7c provides the results for the Jiangsu cities of Nanjing and Wuxi. The local migrants, those from rural Jiangsu, are the comparison group. The table shows that for women, Anhui migrants and migrants for 'other provinces' earn less than those from Jiangsu. For men, there are no significant differences across groups. Henan men are 
present in large enough numbers to be singled out, not so for women. Henan men's wages do not differ significantly from the wages of their Jiangsu counterparts.

Finally, Table $7 \mathrm{~d}$ provides the results for Shanghai. Anhui is again selected as the omitted category. It is the modal category representing 29 per cent of the female migrants in Shanghai and 28 per cent of the male migrants. For women, once again we find no significant differences in pay between migrants from different provinces of origin after controlling for productive characteristics. For men, the 'local migrants' of Anhui and Jiangsu do significantly better in the labor market than migrants from Henan. It appears that this relatively small group of men from Henan in Shanghai (26 out of a total of 368 male migrants) receives markedly discriminatory treatment. Their wages are approximately 24 per cent lower than those of the migrants from Anhui, our base case, after controlling for productive characteristics. In contrast, the wages in Shanghai of migrants from Jiangsu, Sichuan, and Hubei are not significantly different from those of Anhui. The only group of male migrants that stands out as receiving unique treatment in Shanghai, and in this case uniquely negative treatment, is the group of male migrants from Henan.

Overall, in this analysis of migrants' wage treatment based on receiving areas, we find that women's labor markets display strong equanimity of wages across all provinceof-origin groups in each receiving area. The only exception is that female migrants from Anhui working in Jiangsu receive lower wages than their Jiangsu counterparts (that is, intra-provincial Jiangsu migrants). For men, in each of the receiving areas except Jiangsu there seems to be some advantage for the 'home team.' In the sampled cities of Guangdong, rural Guangdong men do better than men from Guangxi. In Zhejiang, Zhejiang men do better than everyone else, but Anhui men also do better than those from Jiangsu and Hubei. And in Shanghai, Anhui and Jiangsu men, who represent the largest groups of migrants to Shanghai, do better than those from Henan and Hubei.

\section{Conclusion}

We argued above that whether there is wage discrimination among the rural-tourban migrants currently employed in Chinese urban labor markets is an empirical question. We noted that evidence of widely held prejudice is a necessary but not 
sufficient condition for wage discrimination. We thus set out to explore whether systemic wage discrimination, based on province of origin, exists in China's urban centers with significant migrant populations. Having carefully cut and sliced our data in many ways, we have accumulated substantial evidence that there is essentially no negative placebased wage discrimination in migrant women's labor markets. Our one minor exception to this generalization is that we found some wage discrimination against women from Anhui who work in Jiangsu. Otherwise, we find that female migrants receive very similar wages, after controlling for productive characteristics, across provincial native place groups. Henan women definitely do not earn lower wages than migrants from other locations. Rather, in the regression based on our full analytic sample, we find that the women from Henan, Anhui, and Jiangsu earn somewhat higher wages, all else equal, than women from Chongqing and all other provinces.

For men, we again find no systemic evidence that Henan migrants do worse in the labor markets than men from other provinces sending out large numbers of migrants. The one exception to this generalization is that we do find significant negative wage discrimination against male migrants from Henan in the Shanghai labor market. The number of Henan men in the Shanghai sample was small but their wages were significantly lower than those migrants from Anhui.

We have amassed two generalizable results for male migrants. The first is related to male migrants from Zhejiang. We find strong and consistent evidence that male migrants from Zhejiang do better, in the sense of receiving higher wages, in almost every location where they migrate. We suspect, given our general findings of wage equality across migrant workers within the labor market, that the difference we observe for Zhejiang migrants is the result of some unobserved differences in productivity or selectivity. These workers from Zhejiang are likely to have higher opportunity costs (due to better and abundant job opportunities in their rural villages), and thus are likely to migrate out, only if they find a desirable higher-wage job. Alternatively, they may be bringing special tools and equipment along to the job and thus their higher pay may be a conflation of returns to both human and physical capital.

Our second generalizable result stands in contrast to Zhang and Zhao's (2013) finding of a positive relationship between migrants' earnings and their distance from 
home. We find, for male migrants, a home team advantage. That is, we find repeated evidence that the 'local' or modal groups of male migrants secure wage premiums over migrants from sending areas with fewer representatives in a particular labor market. It is not clear whether this wage advantage for the 'local' group of migrants is because of better networks, local language advantages or due to discrimination against particular groups viewed as outsiders. These are certainly questions worthy of further analysis. While our results reveal some differences in the determinants of earnings between men's and women's migrant labor markets, no consistent pattern of discrimination against Henan people or migrants from any other particular province emerges. Even though we find no evidence of widespread overt wage discrimination against workers from any specific native place, we fully acknowledge that discrimination by place of origin might be evident in employment levels, as found by Cheng et al (2013), or in hiring processes. ${ }^{13}$ These more inclusive notions of discrimination are not tested here but are deserving of further attention and research.

\footnotetext{
${ }^{13}$ See Maurer-Fazio and Lei (forthcoming) and Maurer-Fazio (2012) for examples of the application of resume audit studies for assessing discrimination in hiring in China's urban labor markets.
} 


\section{References}

Akgüç, M., C. Giulietti, and K. F. Zimmermann (2014) 'The RUMiC longitudinal survey: Fostering research on labor markets in China', IZA Journal of Labor \& Development, 3 (1), 1-14.

Becker, G. S. (1957), The Economics of Discrimination, Chicago: University of Chicago Press.

Brandt, L., and C. A. Holz (2006), 'Spatial price differences in China: Estimates and implications', Economic Development and Cultural Change, 55 (1), 43-86.

Cheng, Z., F. Guo, G. Hugo, and X. Yuan (2013), 'Employment and wage discrimination in the Chinese cities: A comparative study of migrants and locals', Habitat International, 39, 246-55.

Chan, K. W. (2012), 'Migration and development in China: Trends, geography and current issues', Migration and Development, 1 (2), 187-205.

Chan, K.W. and L. Zhang, (1999), 'The hukou system and rural-urban migration in China: Processes and changes', The China Quarterly 160, 818-55.

China Law and Governance Review, (2006) 'Voices against discrimination: An update of recent cases and developments' 3, http://www.chinareview.info/pages/case.htm Accessed 2014-11-14

Connelly, R., K. Roberts and Z. Zheng (2011), 'The settlement of rural migrants in urban China: Some of China's migrants are not 'floating' anymore', Journal of Chinese Economic and Business Studies, 9 (3), 283-300.

Démurger, S., M. Gurgand, S. Li, and X. Yue (2009), 'Migrants as second-class workers in urban China? A decomposition analysis', Journal of Comparative Economics, 37 (4), 610-28.

Fan, C. (1999), 'Migration in a socialist transitional economy: Heterogeneity, socioeconomic and spatial characteristics of migrants in China and Guangdong province', International Migration Review, 33 (4), 954-87.

Fan, C. (2001), 'Migration and labor-market returns in urban China: Results from a recent survey of Guangzhou', Environment and Planning, 33 479-508.

Frijters, P., L. Lee, and X. Meng (2010), 'Jobs, working hours, and remuneration packages of migrants and urban residents', in X. Meng, C. Manning, L. Shi , and T. N. Effendi (eds), The Great Migration: Rural-urban Migration in China and Indonesia, Cheltenham, UK and Northampton, MA, USA: Edward Elgar Publishing, pp. 47-73.

Hare, D. (1999), ' 'Push' versus 'pull' factors in migration outflows and returns: Determinants of migration status and spell duration among China's rural population', Journal of Development Studies, 35 (3), 45-72.

Hughes, J., and M. Maurer-Fazio (2002), 'Effects of marriage, education and occupation on the female/male wage gap in China', Pacific Economic Review, 7 (1), 137-56.

Knight, J., L. Song, and H. Jia. (1999), 'Chinese rural migrants in urban enterprises: Three perspectives', in S. Cook and M. Maurer-Fazio (eds.), The Workers' State Meets the Market: Labor in China's Transition, London: Frank Cass, pp. 73-104.

Kong S. T. (2010), 'Rural-urban migration in China: Survey design and implementation', in X. Meng, C. Manning, L. Shi, and T. N. Effendi (eds.), The Great Migration: Rural-urban Migration in China and Indonesia, Cheltenham, UK and Northampton, MA, USA: Edward Elgar Publishing, pp.135-50. 
Maurer-Fazio, M. and L. Lei, (forthcoming), “As rare as a panda': How facial attractiveness, gender, and occupation affect interview callbacks at Chinese firms', International Journal of Manpower.

Maurer-Fazio, M. and N. Dinh (2004), 'Differential rewards to, and contributions of, education in urban China's segmented labor markets', The Pacific Economic Review, 9 (3), 173-89.

Maurer-Fazio, M. (2012), 'Ethnic discrimination in China's internet job board labor market', IZA Journal of Migration. 1 (12). DOI: 10.1186/2193-9039-1-12 URL: available at http://www.izajom.com/content/1/1/12 (accessed on 12 December 2013).

Meng, X. (2002), 'Are rural migrants outsiders in Chinese urban enterprises?', unpublished manuscript, Research School of Pacific and Asian Studies, Australian National University.

Meng, X. and C. Manning (2010), 'The great migration in China and Indonesia: Trends and institutions' in X. Meng, C. Manning, L. Shi, and T. N. Effendi (eds), The Great Migration: Rural-urban Migration in China and Indonesia, Cheltenham, UK and Northampton, MA, USA: Edward Elgar Publishing, pp. 1-19.

Meng, X. and J. Zhang (2001), 'The two-tier labor market in Urban china: Occupational segregation and wage differentials between urban residents and rural migrants in Shanghai', Journal of Comparative Economics 29 (3), 485-504.

Mincer, J. (1974), Schooling, Experience and Earnings, New York: Columbia University Press.

Nanhu Evening News (2006) 'Henan people need not apply for jobs in the enterprises of Jiaxing City due to regional discrimination?', available at http://www.zj.xinhuanet.com/newscenter/2006-08/23/content_7857125.htm (accessed 14 November 2014).

Phelps, E. S. (1972), 'The statistical theory of racism and sexism', The American Economic Review, 62 (4), 659-661.

Pottinger, M. (2005), 'Henan fights back against years of slurs and jokes', Online Wall Street Journal, Updated April 18, 2005 12:01 a.m. ET available at http://online.wsj.com/articles/SB111377879936309051 (accessed 14 November 2014).

Roberts, K., R. Connelly, Z. Xie and Z. Zheng (2004), 'Patterns of temporary migration of rural women from Anhui and Sichuan provinces of China', The China Journal 52, 49-70.

Shanghai Star (2005), 'Battle Against a Bad Name', re-posted by Guangdong News, available at http://www.newsgd.com/culture/peopleandlife/200505270013.htm Last Updated 2005-05-27 09:19:46. (accessed 14 November 2014).

Tran, N. (2014) A Study of Wage Discrimination against Migrant Workers in China, Senior Thesis: Bates College Department of Economics.

Wang, H.N., F. Guo, and Z.M. Cheng (2013), 'Discrimination in migrant workers' welfare entitlements and benefits in urban labor market: Findings from a four-city study in China', Population, Space and Place, DOI: 10.1002/psp.1810.

Wang, H., F. Guo, and Z. Cheng (2014), 'A distributional analysis of wage discrimination against migrant workers in China's urban labor market', Urban Studies, DOI: 10.1177/0042098014547367. 
Zhang, J., and Z. Zhao (2013), 'Measuring the income-distance tradeoff for rural-urban migrants in China', IZA DP No. 7160.

Zhao, Y. (1999), 'Leaving the countryside: Rural-to-urban migration decisions in China', American Economic Review, 89 (2), 281-86.

Zhu, N. (2002), 'The impacts of income gaps on migration decisions in China', China Economic Review, 13 (2), 213-30. 


\section{Table 1: Numbers of Rural-Urban Migrants in Wage Labor by Place of Origin,}

RUMiC 2008 \& 2009 Data

\begin{tabular}{lcccc} 
& \multicolumn{2}{c}{$\begin{array}{c}\text { Men } \\
\text { Originating Provinces in Wage }\end{array}$} & \multicolumn{2}{c}{$\begin{array}{c}\text { Women Employed in Wage } \\
\text { Labor }\end{array}$} \\
\hline & Frequency & Per cent & Frequency & Per cent \\
Anhui & 661 & 15.43 & 422 & 14.64 \\
Henan & 595 & 13.89 & 288 & 9.99 \\
Sichuan & 522 & 12.18 & 444 & 15.4 \\
Jiangsu & 489 & 11.41 & 340 & 11.79 \\
Hubei & 474 & 11.06 & 327 & 11.34 \\
Chongqing Province & 282 & 6.58 & 249 & 8.64 \\
Guangdong & 265 & 6.19 & 242 & 8.39 \\
Hunan & 220 & 5.14 & 128 & 4.44 \\
Jiangxi & 149 & 3.48 & 73 & 2.53 \\
Zhejiang & 143 & 3.34 & 102 & 3.54 \\
\hline Sub-total: Top 10 provinces of origin & 3800 & 88.7 & 2615 & 90.7 \\
Residual: All other provinces & 484 & 11.3 & 268 & 9.3 \\
\hline Total & 4284 & 100 & 2883 & 100 \\
\hline
\end{tabular}

Note: All wage and salary migrants between the ages of 16 and 65 from the 2008 sample are included. These are supplemented with the wage and salary migrants between the ages of 16 and 65 in the newly drawn 2009 sample. Source: RUMiC 2008 migrant sample plus RUMiC 2009 supplemental migrant sample. 
Table 2 Most Frequent Destinations Cities for Migrants from Particular Source Provinces

\begin{tabular}{|c|c|c|c|c|c|}
\hline Destination Cities & Frequency & Percent & Destination Cities & Frequency & Percent \\
\hline \multicolumn{3}{|c|}{ Anhui Men } & \multicolumn{3}{|c|}{ Anhui Women } \\
\hline Hefei & 193 & 29.2 & Hefei & 100 & 23.7 \\
\hline Bengbu & 105 & 15.89 & Nanjing & 73 & 17.3 \\
\hline Shanghai & 103 & 15.58 & Shanghai & 72 & 17.06 \\
\hline Nanjing & 93 & 14.07 & Bengbu & 68 & 16.11 \\
\hline Hangzhou & 87 & 13.16 & Hangzhou & 44 & 10.43 \\
\hline Ningbo & 40 & 6.05 & Ningbo & 31 & 7.35 \\
\hline Top Destinations & 621 & 93.95 & Top Destinations & 388 & 91.95 \\
\hline Others & 40 & 6.05 & Others & 34 & 8.05 \\
\hline Total & 661 & 100 & Total & 422 & 100 \\
\hline \multicolumn{3}{|c|}{ Henan Men } & \multicolumn{3}{|c|}{ Henan Women } \\
\hline Zhengzhou & 214 & 35.97 & Zhengzhou & 117 & 40.62 \\
\hline Luoyang & 107 & 17.98 & Luoyang & 60 & 20.83 \\
\hline Hangzhou & 57 & 9.58 & Shanghai & 22 & 7.64 \\
\hline Dongguan & 49 & 8.24 & Hangzhou & 20 & 6.94 \\
\hline Shenzhen & 38 & 6.39 & & & \\
\hline Top Destinations & 465 & 78.16 & Top Destinations & 219 & 76.03 \\
\hline Others & 130 & 21.84 & Others & 69 & 23.97 \\
\hline Total & 595 & 100 & Total & 288 & 100 \\
\hline \multicolumn{3}{|c|}{ Sichuan Men } & \multicolumn{3}{|c|}{ Sichuan Women } \\
\hline Chengdu & 260 & 49.81 & Chengdu & 258 & 58.11 \\
\hline Chongqing & 78 & 14.94 & Chongqing & 53 & 11.94 \\
\hline Dongguan & 44 & 8.43 & & & \\
\hline Shenzhen & 35 & 6.7 & & & \\
\hline Top Destinations & 417 & 79.88 & Top Destinations & 311 & 70.05 \\
\hline Others & 105 & 20.12 & Others & 133 & 29.95 \\
\hline Total & 522 & 100 & Total & 444 & 100 \\
\hline \multicolumn{3}{|c|}{ Jiangsu Men } & \multicolumn{3}{|c|}{ Jiangsu Women } \\
\hline Nanjing & 201 & 41.1 & Nanjing & 134 & 39.41 \\
\hline Wuxi & 123 & 25.15 & Wuxi & 116 & 34.12 \\
\hline Shanghai & 97 & 19.84 & Shanghai & 45 & 13.24 \\
\hline Hangzhou & 44 & 9 & & & \\
\hline Top Destinations & 465 & 95.09 & Top Destinations & 295 & 86.77 \\
\hline Others & 24 & 4.91 & Others & 45 & 13.23 \\
\hline Total & 489 & 100 & Total & 340 & 100 \\
\hline \multicolumn{3}{|c|}{ Hubei Men } & \multicolumn{3}{|c|}{ Hubei Women } \\
\hline Wuhan & 289 & 60.97 & Wuhan & 214 & 65.44 \\
\hline Dongguan & 55 & 11.6 & Dongguan & 34 & 10.4 \\
\hline Shenzhen & 40 & 8.44 & & & \\
\hline Top Destinations & 384 & 81.01 & Top Destinations & 248 & 75.84 \\
\hline Others & 90 & 18.99 & Others & 79 & 24.16 \\
\hline Total & 474 & 100 & Total & 327 & 100 \\
\hline
\end{tabular}


Table 3 Most Common Source Provinces for Migrants in Particular Destination Provinces

\begin{tabular}{|c|c|c|c|c|c|}
\hline Destination Cities & Frequency & Percent & Destination Cities & Frequency & Percent \\
\hline \multicolumn{3}{|c|}{ Men in Guangdong } & \multicolumn{3}{|c|}{ Women in Guangdong } \\
\hline Guangdong & 261 & 24.35 & Guangdong & 239 & 36.32 \\
\hline Hunan & 190 & 17.72 & Hunan & 95 & 14.44 \\
\hline Henan & 116 & 10.82 & Hubei & 63 & 9.57 \\
\hline Hubei & 115 & 10.73 & Sichuan & 62 & 9.42 \\
\hline Sichuan & 99 & 9.24 & Guangxi & 49 & 7.45 \\
\hline Guangxi & 79 & 7.37 & Henan & 42 & 6.38 \\
\hline Jiangxi & 50 & 4.66 & Jiangxi & 22 & 3.34 \\
\hline Shaanxi & 34 & 3.17 & & & \\
\hline Guizhou & 25 & 2.33 & & & \\
\hline Sub-Total & 969 & 90.39 & Sub-Total & 572 & 86.92 \\
\hline Residual & 103 & 9.61 & Residual & 86 & 13.08 \\
\hline Total & 1072 & 100 & Total & 658 & 100 \\
\hline \multicolumn{3}{|c|}{ Men in Zhejiang } & \multicolumn{3}{|c|}{ Women in Zhejiang } \\
\hline Anhui & 127 & 20.32 & Zhejiang & 88 & 22.92 \\
\hline Zhejiang & 111 & 17.76 & Anhui & 75 & 19.53 \\
\hline Henan & 76 & 12.16 & Jiangsu & 37 & 9.64 \\
\hline Jiangxi & 64 & 10.24 & Jiangxi & 29 & 7.55 \\
\hline Jiangsu & 55 & 8.8 & Hubei & 28 & 7.29 \\
\hline Hubei & 35 & 5.6 & Henan & 26 & 6.77 \\
\hline Sichuan & 31 & 4.96 & Sichuan & 26 & 6.77 \\
\hline Gansu & 29 & 4.64 & & & \\
\hline Sub-Total & 528 & 84.48 & Sub-Total & 309 & 80.47 \\
\hline Residual & 97 & 15.52 & Residual & 75 & 19.53 \\
\hline Total & 625 & 100 & Total & 384 & 100 \\
\hline \multicolumn{3}{|c|}{ Men in Jiangsu } & \multicolumn{3}{|c|}{ Women in Jiangsu } \\
\hline Jiangsu & 324 & 56.64 & Jiangsu & 250 & 60.1 \\
\hline Anhui & 117 & 20.45 & Anhui & 95 & 22.84 \\
\hline Henan & 24 & 4.2 & & & \\
\hline Sub-Total & 465 & 81.29 & Sub-Total & 345 & 82.94 \\
\hline Residual & 107 & 18.71 & Residual & 71 & 17.06 \\
\hline Total & 572 & 100 & Total & 416 & 100 \\
\hline \multicolumn{3}{|c|}{ Men in Shanghai } & \multicolumn{3}{|c|}{ Women in Shanghai } \\
\hline Anhui & 103 & 27.99 & Anhui & 72 & 28.92 \\
\hline Jiangsu & 97 & 26.36 & Jiangsu & 45 & 18.07 \\
\hline Henan & 26 & 7.07 & Henan & 22 & 8.84 \\
\hline Sichuan & 24 & 6.52 & Sichuan & 21 & 8.43 \\
\hline Hubei & 22 & 5.98 & & & \\
\hline Sub-Total & 272 & 73.92 & Sub-Total & 160 & 64.26 \\
\hline Residual & 96 & 26.08 & Residual & 89 & 35.74 \\
\hline Total & 368 & 100 & Total & 249 & 100 \\
\hline
\end{tabular}


Table 4 Summary Statistics

\begin{tabular}{lcc}
\hline \multicolumn{3}{c}{ Employed Men (excluding self-employed) } \\
Variable & Mean & Standard Deviation \\
\hline Age & 29.03 & 9.64 \\
\% Married & 46 & 0.50 \\
Years of Education & 9.62 & 2.30 \\
Years of work experience & 13.41 & 10.42 \\
Years at current job & 3.31 & 3.57 \\
Number of cities migrated to & 2.07 & 1.91 \\
Years since first migration & 7.64 & 4.86 \\
Hourly income (yuan) & 6.80 & 3.69 \\
Monthly income (yuan) & 1608.77 & 733.66 \\
Hours worked per week & 58.46 & 14.31 \\
Number of observations & 4,287 &
\end{tabular}

\begin{tabular}{lcc}
\multicolumn{3}{c}{ Employed Women (excluding self-employed) } \\
Variable & Mean & Standard Deviation \\
\hline Age & 28.11 & 8.97 \\
\% Married & 49 & 0.50 \\
Years of Education & 9.44 & 2.49 \\
Years of work experience & 12.67 & 10.19 \\
Years at current job & 2.68 & 2.75 \\
Number of cities migrated to & 1.50 & 1.06 \\
Years since first migration & 6.36 & 4.31 \\
Hourly income (yuan) & 5.70 & 2.98 \\
Monthly income (yuan) & 1307.03 & 560.75 \\
Hours worked per week & 56.69 & 13.62 \\
Number of observations & 2,889 &
\end{tabular}


Table 5 Nation-Wide Wage Regressions, Controlling for Places of Origin

Dependent Variable: Natural Log of Hourly Earnings, Adjusted for Regional Cost-of-Living Differences

\begin{tabular}{|c|c|c|c|c|c|c|c|c|}
\hline & \multicolumn{4}{|c|}{ Female Migrants } & \multicolumn{4}{|c|}{ Male Migrants } \\
\hline & Coefficient & Sig. & Std. Err. & Probability & Coefficient & Sig. & Std. Err. & Probability \\
\hline \multicolumn{9}{|l|}{ Individual Characteristics: } \\
\hline Years of Education & 0.048 & $* * *$ & 0.004 & 0.000 & 0.051 & $* * *$ & 0.004 & 0.000 \\
\hline Years of Work Experience & 0.016 & $* * *$ & 0.004 & 0.000 & 0.026 & $* * *$ & 0.003 & 0.000 \\
\hline Years of Work Exp. Squared & 0.000 & $* * *$ & 0.000 & 0.000 & -0.001 & $* * *$ & 0.000 & 0.000 \\
\hline Years at Current Job & 0.027 & $* * *$ & 0.003 & 0.000 & 0.025 & $* * *$ & 0.002 & 0.000 \\
\hline Married & -0.044 & $*$ & 0.023 & 0.058 & 0.044 & $* *$ & 0.019 & 0.021 \\
\hline \multicolumn{9}{|l|}{$\begin{array}{l}\text { Place of Origin: } \\
\text { (Chongqing omitted category) }\end{array}$} \\
\hline Anhui & 0.084 & $*$ & 0.051 & 0.102 & -0.060 & & 0.048 & 0.218 \\
\hline Henan & 0.099 & * & 0.058 & 0.087 & -0.041 & & 0.049 & 0.404 \\
\hline Sichuan & -0.003 & & 0.039 & 0.939 & -0.026 & & 0.039 & 0.496 \\
\hline Jiangsu & 0.112 & $* *$ & 0.053 & 0.034 & -0.030 & & 0.050 & 0.550 \\
\hline Hubei & 0.043 & & 0.053 & 0.416 & -0.096 & $* *$ & 0.049 & 0.049 \\
\hline Guangdong & -0.010 & & 0.052 & 0.853 & -0.056 & & 0.052 & 0.274 \\
\hline Zhejiang & 0.092 & & 0.060 & 0.124 & 0.174 & $* * *$ & 0.057 & 0.002 \\
\hline Hunan & 0.012 & & 0.053 & 0.814 & -0.093 & $*$ & 0.051 & 0.069 \\
\hline Jiangxi & 0.008 & & 0.061 & 0.895 & -0.092 & $*$ & 0.056 & 0.102 \\
\hline Guangxi & -0.058 & & 0.077 & 0.446 & -0.137 & $* *$ & 0.062 & 0.026 \\
\hline Shandong & 0.032 & & 0.073 & 0.656 & 0.035 & & 0.062 & 0.568 \\
\hline Shaanxi & -0.031 & & 0.069 & 0.657 & -0.056 & & 0.060 & 0.349 \\
\hline Gansu & $\mathrm{n} / \mathrm{a}$ & & & & -0.023 & & 0.067 & 0.724 \\
\hline Guizhou & $\mathrm{n} / \mathrm{a}$ & & & & -0.001 & & 0.069 & 0.991 \\
\hline Fujian & $\mathrm{n} / \mathrm{a}$ & & & & 0.129 & & 0.091 & 0.155 \\
\hline Other Provinces & 0.048 & & 0.052 & 0.363 & 0.034 & & 0.055 & 0.533 \\
\hline \multicolumn{9}{|l|}{ Other: } \\
\hline Surveyed in 2008 & -0.136 & $* * *$ & 0.015 & 0.000 & -0.153 & $* * *$ & 0.013 & 0.000 \\
\hline Constant & 0.988 & $* * *$ & 0.065 & 0.000 & 1.086 & $* * *$ & 0.058 & 0.000 \\
\hline Number of Observations & 2,883 & & & & 4,280 & & & \\
\hline R-squared & 0.265 & & & & 0.259 & & & \\
\hline
\end{tabular}

*** Significant at $1 \% ; * *$ Significant at $5 \% ; *$ Significant at $10 \%$

Note: Estimated using areg command in Stata, destination cities are included as fixed effects. Coefficients not reported. 


\section{Table 6 At Destinations of Henan Migrants: Wage Regressions, Controlling for Migrants' Places of Origin}

Dependent Variable: Natural Log of Hourly Earnings, Adjusted for Regional Cost-of-Living Differences

Female Migrants Male Migrants

Coefficient Sig. Std. Err. Probability Coefficient Sig. Std. Err. Probability

\begin{tabular}{|c|c|c|c|c|c|c|c|c|}
\hline \multicolumn{9}{|l|}{ Individual Characteristics: } \\
\hline Years of Education & 0.041 & $* * *$ & 0.008 & 0.000 & 0.054 & $* * *$ & 0.006 & 0.000 \\
\hline Years of Work Experience & 0.015 & $*$ & 0.009 & 0.093 & 0.025 & $* * *$ & 0.005 & 0.000 \\
\hline Years of Work Exp. Squared & 0.000 & $* *$ & 0.000 & 0.028 & -0.001 & $* * *$ & 0.000 & 0.000 \\
\hline Years at Current Job & 0.023 & $* * *$ & 0.007 & 0.002 & 0.023 & $* * *$ & 0.004 & 0.000 \\
\hline Married & -0.014 & & 0.054 & 0.798 & 0.020 & & 0.034 & 0.556 \\
\hline \multicolumn{9}{|l|}{$\begin{array}{l}\text { Place of Origin: } \\
\text { (Henan omitted category) }\end{array}$} \\
\hline Anhui & -0.021 & & 0.073 & 0.779 & 0.014 & & 0.062 & 0.826 \\
\hline Jiangsu & -0.143 & $*$ & 0.082 & 0.082 & -0.117 & & 0.081 & 0.146 \\
\hline Zhejiang & -0.018 & & 0.082 & 0.824 & 0.200 & $* * *$ & 0.065 & 0.002 \\
\hline Sichuan & -0.100 & & 0.092 & 0.277 & 0.004 & & 0.053 & 0.938 \\
\hline Jiangxi & -0.086 & & 0.091 & 0.347 & -0.080 & & 0.060 & 0.182 \\
\hline Hubei & 0.067 & & 0.095 & 0.479 & -0.039 & & 0.051 & 0.441 \\
\hline Guangdong & $\mathrm{n} / \mathrm{a}$ & & & & -0.069 & & 0.058 & 0.236 \\
\hline Hunan & $\mathrm{n} / \mathrm{a}$ & & & & -0.062 & & 0.050 & 0.218 \\
\hline Guangxi & $\mathrm{n} / \mathrm{a}$ & & & & -0.064 & & 0.072 & 0.371 \\
\hline Shaanxi & $\mathrm{n} / \mathrm{a}$ & & & & -0.034 & & 0.068 & 0.617 \\
\hline Gansu & $\mathrm{n} / \mathrm{a}$ & & & & 0.062 & & 0.079 & 0.431 \\
\hline Guizhou & $\mathrm{n} / \mathrm{a}$ & & & & -0.025 & & 0.072 & 0.73 \\
\hline ChongqingP & $\mathrm{n} / \mathrm{a}$ & & & & 0.184 & $*$ & 0.107 & 0.085 \\
\hline Other Provinces & -0.151 & $*$ & 0.079 & 0.057 & 0.105 & & 0.082 & 0.199 \\
\hline \multicolumn{9}{|l|}{ Other: } \\
\hline Surveyed in 2008 & -0.183 & $* * *$ & 0.033 & 0.000 & -0.187 & $* * *$ & 0.023 & 0.000 \\
\hline Constant & 1.199 & $* * *$ & 0.117 & 0.000 & 1.085 & $* * *$ & 0.082 & 0.000 \\
\hline Number of Observations & 663 & & & & 1,446 & & & \\
\hline R-squared & 0.215 & & & & 0.301 & & & \\
\hline
\end{tabular}

*** Significant at $1 \% ; * *$ Significant at $5 \%$; Significant at $10 \%$

Note: Estimated using areg command in Stata, destination cities are included as fixed effects. Coefficients not reported. Men's sample includes all the male migrants who are in Zhengzhou, Luoyang, Hangzhou, Dongguan and Shenzhen. Women's sample includes all the female migrants who are in Zhengzhou, Luoyang, Shanghai and Hangzhou 


\section{Table 7a All Migrants in Guangdong-Wage Regressions, Controlling for Place of Origin}

Dependent Variable: Natural Log of Hourly Earnings, Adjusted for Regional Cost-of-Living Differences

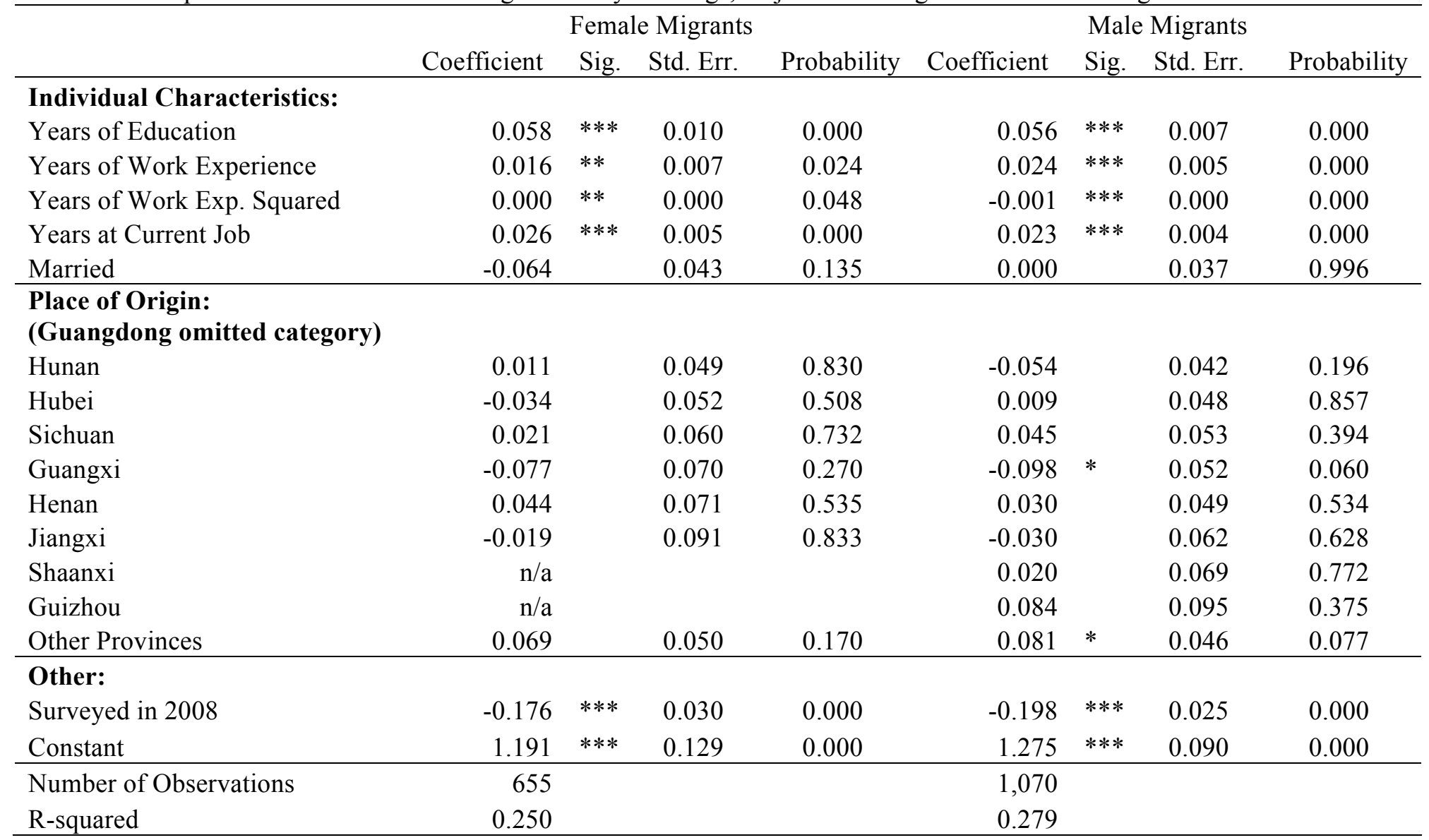

*** Significant at $1 \%$;* Significant at $5 \%$; Significant at $10 \%$

Note: Estimated using areg command in Stata, destination cities are included as fixed effects. Coefficients not reported. Sample limited to migrants currently in the cities of Guangzhou, Dongguan and Shenzhen which are all in Guangdong province. 
Table 7b All Migrants in Zhejiang-- Wage Regressions, Controlling for Place of Origin Dependent Variable: Natural Log of Hourly Earnings, Adjusted for Regional Cost-of-Living Differences

\begin{tabular}{|c|c|c|c|c|c|c|c|c|}
\hline \multirow[b]{2}{*}{$\begin{array}{l}\text { Individual } \\
\text { Characteristics: }\end{array}$} & \multicolumn{4}{|c|}{ Female Migrants } & \multicolumn{4}{|c|}{ Male Migrants } \\
\hline & Coefficient & Sig. & Std. Err. & Probability & Coefficient & Sig. & Std. Err. & Probability \\
\hline Years of Education & 0.057 & $* * *$ & 0.010 & 0.000 & 0.056 & $* * *$ & 0.010 & 0.000 \\
\hline $\begin{array}{l}\text { Years of Work Experience } \\
\text { Years of Work Exp. }\end{array}$ & 0.027 & $* * *$ & 0.010 & 0.006 & 0.033 & $* * *$ & 0.008 & 0.000 \\
\hline Squared & -0.001 & $* * *$ & 0.000 & 0.000 & -0.001 & $* * *$ & 0.000 & 0.000 \\
\hline Years at Current Job & 0.019 & $* * *$ & 0.008 & 0.023 & 0.031 & $* * *$ & 0.007 & 0.000 \\
\hline Married & 0.045 & & 0.064 & 0.476 & 0.110 & $* *$ & 0.050 & 0.029 \\
\hline \multicolumn{9}{|l|}{$\begin{array}{l}\text { Place of Origin: } \\
\text { (Anhui omitted category) }\end{array}$} \\
\hline Zhejiang & 0.050 & & 0.065 & 0.437 & 0.164 & $* * *$ & 0.061 & 0.007 \\
\hline Jiangsu & 0.006 & & 0.069 & 0.929 & -0.182 & $* *$ & 0.076 & 0.017 \\
\hline Jiangxi & -0.006 & & 0.085 & 0.940 & -0.069 & & 0.070 & 0.329 \\
\hline Hubei & 0.040 & & 0.103 & 0.702 & -0.176 & $* *$ & 0.087 & 0.043 \\
\hline Henan & 0.126 & & 0.087 & 0.148 & 0.019 & & 0.069 & 0.785 \\
\hline Sichuan & 0.008 & & 0.088 & 0.924 & -0.092 & & 0.088 & 0.294 \\
\hline Gansu & $\mathrm{n} / \mathrm{a}$ & & & & 0.045 & & 0.092 & 0.627 \\
\hline Other Provinces & -0.068 & & 0.062 & 0.271 & 0.063 & & 0.063 & 0.320 \\
\hline \multicolumn{9}{|l|}{ Other: } \\
\hline Surveyed in 2008 & -0.091 & $* *$ & 0.041 & 0.027 & -0.046 & & 0.037 & 0.220 \\
\hline Constant & 1.008 & $* * *$ & 0.123 & 0.000 & 1.125 & $* * *$ & 0.131 & 0.000 \\
\hline Number of Observations & 381 & & & & 625 & & & \\
\hline R-squared & 0.235 & & & & 0.234 & & & \\
\hline
\end{tabular}

*** Significant at $1 \%$; * Significant at $5 \%$; Significant at $10 \%$

Note: Estimated using areg command in Stata, destination cities are included as fixed effects. Coefficients not reported. Sample limited to migrants currently in Hangzhou and Ningbo which are both in Zhejiang province. 


\section{Table 7c All Migrants in Jiangsu-- Wage Regressions, Controlling for Place of Origin}

Dependent Variable: Natural Log of Hourly Earnings, Adjusted for Regional Cost-of-Living Differences

\begin{tabular}{|c|c|c|c|c|c|c|c|c|}
\hline & \multicolumn{4}{|c|}{ Female Migrants } & \multicolumn{4}{|c|}{ Male Migrants } \\
\hline & Coefficient & Sig. & Std. Err. & Probability & Coefficient & Sig. & Std. Err. & Probability \\
\hline \multicolumn{9}{|l|}{ Individual Characteristics: } \\
\hline Years of Education & 0.014 & & 0.012 & 0.250 & 0.052 & $* * *$ & 0.011 & 0.000 \\
\hline Years of Work Experience & 0.000 & & 0.008 & 0.968 & 0.015 & $* *$ & 0.006 & 0.015 \\
\hline Years of Work Exp. Squared & 0.000 & & 0.000 & 0.460 & 0.000 & $* * *$ & 0.000 & 0.001 \\
\hline Years at Current Job & 0.035 & $* * *$ & 0.008 & 0.000 & 0.029 & $* * *$ & 0.005 & 0.000 \\
\hline Married & -0.049 & & 0.058 & 0.392 & 0.026 & & 0.049 & 0.603 \\
\hline \multicolumn{9}{|l|}{$\begin{array}{l}\text { Place of Origin: } \\
\text { (Jiangsu omitted category) }\end{array}$} \\
\hline Anhui & -0.092 & $*$ & 0.051 & 0.071 & -0.075 & & 0.050 & 0.140 \\
\hline Henan & $\mathrm{n} / \mathrm{a}$ & & & & 0.078 & & 0.093 & 0.400 \\
\hline Other Provinces & -0.148 & $* *$ & 0.056 & 0.009 & 0.016 & & 0.050 & 0.750 \\
\hline \multicolumn{9}{|l|}{ Other: } \\
\hline Surveyed in 2008 & 0.041 & & 0.040 & 0.312 & -0.022 & & 0.035 & 0.535 \\
\hline Constant & 1.679 & $* * *$ & 0.142 & 0.000 & 1.227 & $* * *$ & 0.138 & 0.000 \\
\hline Number of Observations & 420 & & & & 573 & & & \\
\hline R-squared & 0.168 & & & & 0.185 & & & \\
\hline
\end{tabular}

*** Significant at $1 \% ; * *$ Significant at $5 \% ; *$ Significant at $10 \%$

Note: Estimated using areg command in Stata, destination cities are included as fixed effects. Coefficients not reported.

Sample limited to migrants currently in Nanjing and Wuxi which are both in Jiangsu province. 


\section{Table 7d All Migrants in Shanghai-Wage Regressions, Controlling for Place of Origin}

Dependent Variable: Natural Log of Hourly Earnings, Adjusted for Regional Cost-of-Living Differences

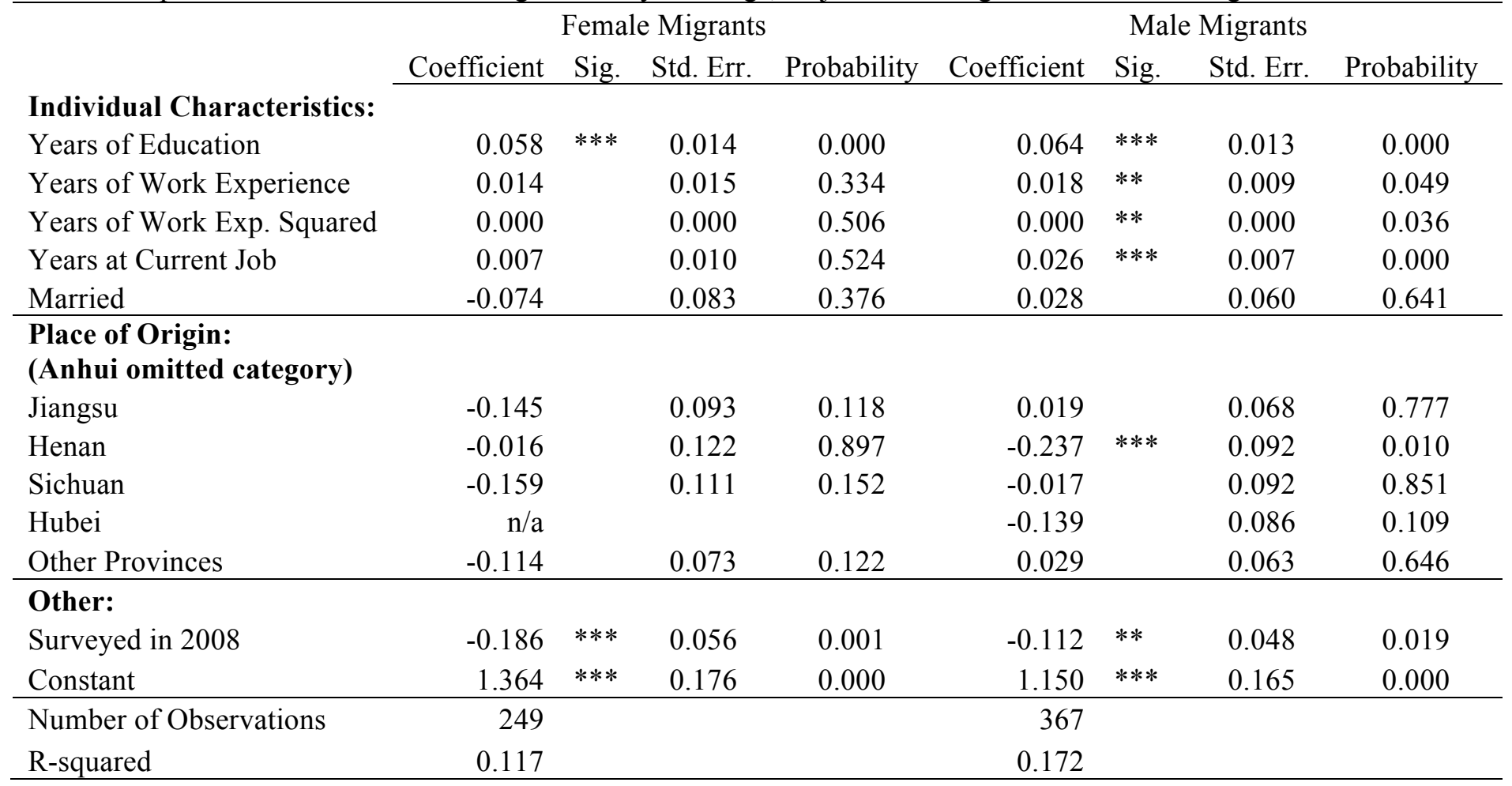

*** Significant at $1 \%$; * Significant at 5\%; Significant at $10 \%$

Note: Estimated using reg command in Stata. Sample limited to migrants currently in the city of Shanghai. 